\title{
Veterans Perceptions of Satisfaction and Convenience with Anticoagulants for Atrial Fibrillation: Warfarin versus Direct Oral Anticoagulants
}

This article was published in the following Dove Press journal: Patient Preference and Adherence

\author{
Hillary J Mull $\mathbb{D}^{1,2}$ \\ Marlena H Shin (D) \\ Ryann L Engle iD ' \\ Amy M Linsky (iD) 1,3,4 \\ Emily Kalver \\ Rebecca Lamkin' \\ Jennifer L Sullivan (iD) ${ }^{1,5}$ \\ 'VA Boston Healthcare System, Center \\ for Healthcare Organization and \\ Implementation Research (CHOIR), \\ Boston, MA, USA; ${ }^{2}$ Department of \\ Surgery, Boston University School of \\ Medicine, Boston, MA, USA; ${ }^{3}$ General \\ Internal Medicine, Boston University \\ School of Medicine, Boston, MA, USA; \\ ${ }^{4}$ General Internal Medicine, VA Boston \\ Healthcare System, Boston, MA, USA; \\ ${ }^{5}$ Department of Health Law, Policy and \\ Management, Boston University School \\ of Public Health, Boston, MA, USA
}

Correspondence: Hillary J Mull

VA Boston Healthcare System, Center for Healthcare Organization and Implementation Research (CHOIR),

Boston, MA, USA

Tel + I-857-364-2766

Email Hillary.Mull@va.gov
Background: Atrial fibrillation (AFib) is associated with high morbidity and mortality. Traditionally, AFib was treated with warfarin, yet recent evidence suggests patients may favor direct oral anticoagulants (DOACs). Variation in preferences is common and we explored patients' perceptions of satisfaction and convenience of DOACs versus warfarin within the Veterans Health Administration (VA).

Patients and Methods: We administered a cross-sectional survey, the Perception of Anticoagulant Treatment Questionnaire 2 (PACT-Q2), to Veterans residing in New England, age $\geq 65$, diagnosed with AFib, and actively taking anticoagulant medication in fiscal year 2018. Survey recipients were randomly selected among patients on warfarin $(n=200)$ or DOACs $(n=200)$. A selection of survey respondents agreed to a follow-up semistructured interview $(n=16)$ to further investigate perceptions of satisfaction and convenience.

Results: Of 400 patients, 187 completed the PACT-Q2 survey (49\% on DOACs; $51 \%$ on warfarin). DOACs received significantly higher convenience ratings than warfarin (87.6, SD 13.5 vs 81.1 , SD 18.8; $\mathrm{p}=0.007)$; there was no difference in satisfaction (64.2, SD $20.5 \mathrm{SD}$, warfarin vs, 67.3, SD 19.4, DOACs). Interview results showed that participants perceived their treatment to be convenient. However, participants expressed challenges related to the convenience of taking warfarin or DOACs, such as warfarin users having to follow dietary recommendations or DOAC users desiring some additional monitoring to answer questions or concerns. Overall, warfarin and DOAC users reported satisfaction with ongoing monitoring methods, although a few DOAC users expressed uncertainties with the frequency of monitoring. For most participants, concerns about side effects did not differ by anticoagulant type nor affect satisfaction.

Conclusion: Our survey and interview results showed variable patient satisfaction and perceptions of convenience with both DOACs and warfarin. Although DOACs are increasingly prescribed for AFib, some Veterans felt that regular follow-up on warfarin was advantageous. Our findings demonstrate the importance of patient-centered decisionmaking in AFib treatment in the VA patient population.

Keywords: qualitative research, patient-centered care, patient perceptions, atrial fibrillation, anticoagulant medication, Veterans

\section{Introduction}

More than 3 million individuals in the United States live with atrial fibrillation (AFib), a cardiovascular condition with substantial morbidity and mortality, including a five-fold increased risk of ischemic stroke. ${ }^{1}$ One component of treatment 
focuses on preventing blood clots to reduce stoke risk. Vitamin K antagonists (eg, warfarin) have successfully reduced the risk of stroke by two-thirds, but the effectiveness of these methods is hampered by narrow therapeutic ranges and required monthly laboratory monitoring to prevent over-anticoagulation and associated risk for hemorrhage. ${ }^{2}$ The anticoagulation treatment options for patients with AFib rapidly changed with the introduction of direct oral anticoagulants (DOACs). DOACs often replace warfarin, when clinically appropriate, because they do not require laboratory monitoring. ${ }^{1,3}$ Many European professional societies now endorse DOACs over warfarin for stroke prevention; ${ }^{4}$ however, there is no consensus recommendation in the US at this time, including in the nation's largest publicly funded healthcare system, the Veteran's Health Administration (VA).

Initial clinical trials provide good evidence that DOACs (dabigatran, rivaroxaban, and apixaban) are either superior or non-inferior to warfarin in the overall population on a variety of clinical outcomes including stroke, mortality, and bleeding risk. ${ }^{5}$ Beyond outcomes like clinical benefits and side effects, other considerations of anticoagulation include costs and feasibility of using the medication. When DOACs were introduced, they were more expensive than warfarin, but were considered easier for patients to use. Compared to warfarin, DOACs do not need ongoing blood testing, have fewer drug-drug interactions, and require no dietary restrictions. For these reasons, many clinicians now express a preference for DOACs over warfarin. ${ }^{6}$

Evidence suggests that clinicians' perceptions of anticoagulation treatment may not always align with those of patients. $^{7}$ A qualitative meta-synthesis study of patient and provider perceptions of anticoagulation concluded that the patient experience is not well understood by providers. ${ }^{8}$ While some studies found patients' preferred DOACs because they were easy to take and did not require testing, ${ }^{9-11}$ other patients favored warfarin explicitly because they were reassured by ongoing laboratory monitoring. ${ }^{12}$ Warfarin was also sometimes preferred by patients because, unlike DOACs, warfarin has an antidote in the event of a bleeding complication. ${ }^{3,13}$ Considerable variation in patient preferences is seen in studies using a variety of methodological approaches, including surveys of patient experience, ${ }^{14}$ economic preference analysis of willingness to pay for DOAC instead of warfarin, ${ }^{15}$ a vignette-based questionnaire, ${ }^{11}$ a treatment trade-off evaluation, ${ }^{12}$ and open-ended patient interviews. ${ }^{11}$ This contrasts with more consistent clinician proclivity toward DOACs. As warfarin is increasingly shown to be an inferior treatment modality, there are implications for patient outcomes if patients' perspectives are not considered. ${ }^{16}$

Engaging patients in shared decision-making is the cornerstone of patient-centered care. ${ }^{13}$ Clinicians must solicit patient perceptions about medication goals and factors related to convenience and satisfaction with anticoagulation. ${ }^{17}$ Despite the numerous studies of patient's perceptions of warfarin or DOACs, more data are needed to understand variation in subpopulations using these medications. ${ }^{4,18,19}$ Particularly within the VA, where patients have higher rates of comorbid mental illness and are more likely to live in rural residential areas with limited access to care, ${ }^{20}$ the underlying reasons behind perceptions of convenience and satisfaction with anticoagulants may differ from prior research. This exploratory study seeks to fill this gap by assessing VA patient perceptions of AFib anticoagulation treatment using two methods: a validated survey and patient interviews.

\section{Patients and Methods}

To assess VA patients' perceptions of DOACs versus warfarin, we conducted this study using two methods: 1) a cross-sectional survey administered to Veterans from May-June 2019, and 2) qualitative semi-structured interviews with Veterans from July-August 2019. We conducted this study in accordance with the Declaration of Helsinki and the approval of the VA Boston Healthcare System Institutional Review Board and included support to obtain verbal informed consent from Veterans. The first and second authors had full access to all data in the study and take full responsibility for the data analysis.

\section{Survey}

Survey

We used the 20-question Perception of Anticoagulant Treatment Questionnaire revision 2 (PACT-Q2), which was developed and validated by Sanofi-Aventis, and has robust psychometric properties for two dimensions: convenience and satisfaction related to treatment expectations. $^{21,22}$ The survey has been used in multiple patient populations to compare specific DOACs and warfarin in patients with AFib. ${ }^{14,23-25}$ The PACT-Q2 domain of convenience assesses concern with difficulty taking medication and how bothered the patient is by follow-up 
required, while the domain of satisfaction explores independence and expectations of side effects. ${ }^{21}$

\section{Data Sources}

Patients were identified using electronic health recordextracted data stored in the VA Corporate Data Warehouse, including diagnoses (inpatient and outpatient); pharmacy orders and fills; drug names and dosages; and patient's name, address and date of birth. We also used data from Medicare administrative files accessible within the VA to identify Veterans obtaining anticoagulant medication from non-VA sources.

\section{Sample}

VA patients who were dually enrolled in VA and Medicare (excluding Medicare Advantage patients due to differences in drug cost-sharing that may have biased decision-making), age 65 years or older, diagnosed with AFib, and actively taking anticoagulant medication in fiscal year 2018. Our random sample included 400 patients, stratified evenly to ensure $50 \%$ had an active prescription for a DOAC (apixaban, dabigatran, edoxaban, or rivaroxaban) and 50\% were prescribed warfarin, according to VA pharmacy data. We limited the study to patients with valid home addresses in the New England area. We selected this sample for our analysis because we wanted to ensure we captured the extent of anticoagulation use (whether prescribed by VA or Medicare providers). We identified the type of anticoagulant the patient was actively taking; other anticoagulants prescribed in the prior four years; the VA medical center (VAMC) at which the anticoagulant was prescribed; and Veteran age, sex, race and comorbidities (measured with the Agency for Healthcare Research and Quality (AHRQ) Comorbidity Software). ${ }^{26}$

\section{Data Collection}

To recruit patients for the survey, we used a multiple mailing strategy, ${ }^{27}$ which consisted of an introductory letter with an opt-out option; a survey packet (eg, cover letter, project fact sheet, opt-out card, $\$ 5$ incentive, and survey); and a thank you/reminder letter. If the Veteran completed the survey, they received a $\$ 15$ VA cashier's check.

\section{Analysis}

We performed psychometric testing to confirm whether the PACT-Q2 domains for convenience and satisfaction emerged in our VA sample of AFib patients. We reviewed data quality and missingness of each item as well as the percent of items at the floor and ceiling of each question. We randomly divided the survey responses equally and conducted an exploratory factor analysis (EFA) with varimax rotation on the derivation sample and a multi-trait scaling analysis (MTA) based on a priori PACT-Q2 scales on the validation sample.

Next, we analyzed differences in convenience and satisfaction scores by DOAC versus warfarin, and then by drug name (DOACs: apixaban, rivaroxaban and dabigatran, versus warfarin). We compared differences in mean scores using a $t$-test or analysis of variance test with Bonferroni adjustment, as appropriate. Analyses were conducted using SAS statistical software, version 9.2.

\section{Interviews}

\section{Sample}

To recruit Veterans for the telephone interviews, survey respondents could opt-in by answering affirmatively to the survey item:

Are you willing to participate in a 20 to 45 -minute telephone interview with a research study team member at a later date to share with us your thoughts on your anticoagulation medication?

Our goal was to recruit 20 Veteran patients for these interviews with representation by those taking a DOAC or warfarin.

\section{Interview Guide}

Interviews were conducted using a guide that was developed by qualitative research experts and reviewed by an Internal Medicine clinician. The semi-structured interview guide focused on questions that would elicit responses about the two PACT-Q2 domains of convenience and satisfaction. The questions allowed Veteran participants to reflect on their experiences and preferences with their anticoagulant so that we could understand their perceptions about their anticoagulation treatment. Figure 1 presents examples of interview questions.

\section{Data Collection}

We used a two-step process to recruit the Veterans for the semi-structured telephone interviews. First, we contacted via mail 20 survey respondents representing different states in New England who had informed us that they would like to be contacted for a telephone interview. Next, we followed-up on the mailing by calling the Veteran to discuss the study and schedule a one-time 


\begin{tabular}{|l|l|}
\hline & Questions \\
\hline 1 & $\begin{array}{l}\text { I understand that you are taking an oral anticoagulation medicine/blood thinner for } \\
\text { atrial fibrillation. Which oral anticoagulation medicine/blood thinner are you taking? } \\
\text { When did you start taking this medicine? }\end{array}$ \\
\hline 2 & $\begin{array}{l}\text { Do you remember when your provider first mentioned this particular medicine? What } \\
\text { did they cover in that conversation? }\end{array}$ \\
\hline 3 & $\begin{array}{l}\text { Did you have any concerns about taking this medicine? If so, how were those } \\
\text { concerns met? }\end{array}$ \\
\hline 4 & $\begin{array}{l}\text { Have you ever been prescribed any other anticoagulation medicines besides the one } \\
\text { you are currently taking? Why did you switch to the anticoagulation medicine that you } \\
\text { are currently taking? }\end{array}$ \\
\hline 5 & What expectations related to your health did you have when starting this medicine? \\
\hline 6 & $\begin{array}{l}\text { Can you tell me about some of your experiences with the medicine that you are } \\
\text { currently taking? }\end{array}$ \\
\hline 7 & How has this medicine affected your health? \\
\hline 8 & What side effects have you experienced from this medicine? \\
\hline
\end{tabular}

Figure I Example of interview questions.

telephone interview at a time convenient for the Veteran. To meet recruitment goals, we conducted a second recruitment wave and contacted another 20 potential participants following the same two-step process. Two experienced health services researchers [MS, RE] conducted the semistructured interviews. These interviews averaged approximately 30 minutes each, and interviewees were provided a \$20 incentive for participation. We obtained verbal informed consent from Veterans to conduct interviews and publish anonymized results; all interviews were audiorecorded and professionally transcribed.

\section{Analysis}

We used the interview transcripts as the primary source for directed content analyses. Three health services researchers (MS, RE, JS) jointly coded one interview transcript for evidence of the established domains, convenience and satisfaction, using NVivo 11 qualitative software. Coders then met to compare the similarities and differences in their coding of the domains and reach consensus on coding classification. After coders reached inter-coder agreement and consensus on the classification of evidence for the two domains with the first transcript, thereafter, the remaining transcripts were divided and coded separately by the three researchers. Next, coding reports were generated in NVivo and were reviewed. The content of the coded evidence in the reports was synthesized and organized to enable the identification of themes for each domain. Finally, the data were condensed into identified themes for each of the PACT-Q2 domains (convenience and satisfaction) in a summary document, which also included representative quotes for each theme. As part of this process, we also described Veterans' perceptions about their warfarin and DOAC treatment.

\section{Results}

Within the eight VA medical centers in New England, we identified 2365 VA patients with AFib over age 65, dually enrolled in Medicare, and taking anticoagulant medication for AFib. Among the 657 (27.7\%) patients taking warfarin, 37 were switched to warfarin from a DOAC with the prior four years. There were $1708(72.2 \%)$ patients taking a DOAC, and 539 (31.6\%) of these had switched from warfarin to DOAC in the previous four years. No patients were using the DOAC edoxaban.

\section{Survey}

There were 184 patients (55\%) who returned completed surveys and were included in the study population; an additional 33 opted out and 3 returned incomplete surveys. Survey respondents were primarily male (98\%), consistent with the VA patient population age 65 and older. ${ }^{28}$ The mean age was 78.8 years, standard deviation (SD) 7.4 years (Table 1). We identified 32 (17\%) patients with dementia and/or serious mental illness (eg, bipolar). 
Table I Survey Sample Characteristics $(n=184)$

\begin{tabular}{|c|c|}
\hline Characteristics & $\mathbf{N}(\%)$ \\
\hline \multicolumn{2}{|l|}{ Current anticoagulation medication } \\
\hline Apixaban & $50(27.17 \%)$ \\
\hline Dabigatran & $18(9.78 \%)$ \\
\hline Rivaroxaban & $22(11.96 \%)$ \\
\hline Warfarin & 94 (51.09\%) \\
\hline \multicolumn{2}{|l|}{ Changed medication in prior 4 years } \\
\hline Warfarin to DOAC & $21(11.41 \%)$ \\
\hline DOAC to Warfarin & $5(2.72 \%)$ \\
\hline \multicolumn{2}{|l|}{ VA Medical Center } \\
\hline Augusta, ME & $36(19.57 \%)$ \\
\hline White River Junction, VT & $19(10.33 \%)$ \\
\hline Bedford, MA & $14(7.61 \%)$ \\
\hline VA Boston HCS, MA & $33(17.93 \%)$ \\
\hline Manchester, NH & 17 (9.24\%) \\
\hline Leeds, MA & $19(10.33 \%)$ \\
\hline Providence, RI & $13(7.07 \%)$ \\
\hline West Haven VAMC, CT & $33(17.93 \%)$ \\
\hline \multicolumn{2}{|l|}{ Demographics } \\
\hline Number of men & $180(97.83 \%)$ \\
\hline Age, years (mean, standard deviation) & $78.84(7.36)$ \\
\hline Number of white patients & $175(95.11 \%)$ \\
\hline \multicolumn{2}{|l|}{ Comorbid conditions } \\
\hline Valvular Disease & $58(31.52 \%)$ \\
\hline Venous thromboembolism & II (5.98\%) \\
\hline Congestive Heart Failure & $52(28.26 \%)$ \\
\hline Hypertension & I55 (84.24\%) \\
\hline Diabetes & 75 (40.76\%) \\
\hline Liver Failure & $7(3.8 \%)$ \\
\hline Ethanol Abuse & $15(8.15 \%)$ \\
\hline Pericarditis and Pericardial Effusion & $7(3.8 \%)$ \\
\hline Fluid and Electrolyte Disorders & $32(17.39 \%)$ \\
\hline Depression & 24 (13.04\%) \\
\hline Dementia & $7(3.8 \%)$ \\
\hline Anxiety & $18(9.78 \%)$ \\
\hline Serious Mental Illness (PTSD, Bipolar) & $26(14.13 \%)$ \\
\hline Cancer & $24(13.04 \%)$ \\
\hline Pulmonary Circulatory Disorders & I8 (9.78\%) \\
\hline Chronic Pulmonary Disease & $49(26.63 \%)$ \\
\hline Paralysis & $2(1.09 \%)$ \\
\hline Epilepsy & $2(1.09 \%)$ \\
\hline Neurological Disorders & $12(6.52 \%)$ \\
\hline Hypothyroidism & 25 (13.59\%) \\
\hline Peptic Ulcer Disease (excl. Bleeding) & I (0.54\%) \\
\hline Rheumatoid Arthritis/Collagen Vascular Diseases & $7(3.8 \%)$ \\
\hline Reduced Platelet Function & $6(3.26 \%)$ \\
\hline Obesity & $60(32.61 \%)$ \\
\hline Weight Loss & $4(2.17 \%)$ \\
\hline
\end{tabular}

Approximately half of the respondents were taking warfarin at the time of the survey (51\%), compared to $49 \%$ on DOACs, but $11 \%$ of respondents had switched from warfarin to a DOAC sometime in the previous four years.

Psychometric testing of the PACT-Q2 survey on our Veteran population confirmed the two factors, convenience and satisfaction (Table 2). Eigenvalues from the EFA were moderate for satisfaction (6.03) and borderline for convenience (2.43) in the dual-factor solution. The subsequent MTA showed $100 \%$ item discriminant validity. Internal consistency was high for convenience $(\alpha=0.86)$ and for satisfaction $(\alpha=0.81)$.

On average, survey respondents rated convenience more highly than satisfaction, 87.88, SD 16.69 versus 67.86, SD 19.96 (Table 3). There was no significant difference in ratings for patients with comorbid dementia or serious mental illness. In tests for differences in means across groups, only ratings for convenience differed significantly between medication class: DOACs were rated as more convenient than warfarin, 87.62, SD 13.46 versus 81.09, SD 18.8, $\mathrm{p}=0.007$. In comparisons by medication name, only the DOAC rivaroxaban had a significantly higher convenience score than warfarin, 92.47, SD 7.43 versus 81.09 , SD $18.8, p=0.022$ in the analysis of variance test.

\section{Interviews}

Our final interview sample included 16 male Veteran participants (10 prescribed warfarin; 6 prescribed DOACs -2 of the 6 had previously taken warfarin) across five states in New England.

\section{Convenience}

Overall, both groups of participants taking either warfarin or a DOAC perceived their treatment to be convenient. There were four main themes about convenience that emerged from the data: 1) ability to take anticoagulant as directed; 2) dietary recommendation while taking an anticoagulant; 3) impact of taking anticoagulant on daily life; 4) reaction to laboratory monitoring required with anticoagulant. Below we highlight Veterans' experiences and challenges that were noted within these themes. 


\begin{tabular}{|c|c|c|c|c|c|c|c|c|c|c|c|c|c|c|c|c|}
\hline \multirow{3}{*}{ 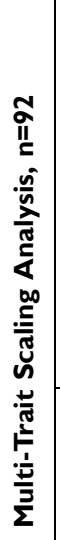 } & \multirow{2}{*}{ 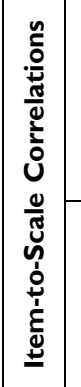 } & \multirow{2}{*}{ 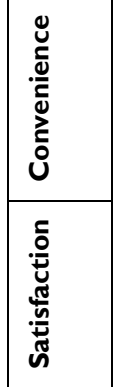 } & i. & $\overline{\hat{o}}$ & : & : & 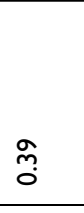 & $\stackrel{\circ}{0}$ & $\stackrel{\infty}{\stackrel{\infty}{0}}$ & $\stackrel{\text { L̊ }}{0}$ & $\stackrel{\substack{m \\
0}}{0}$ & 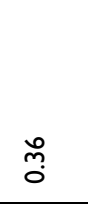 & 嵌 & $\stackrel{m}{m}$ & & \multirow{2}{*}{ 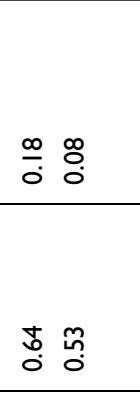 } \\
\hline & & & $\stackrel{\circ}{\circ} \frac{\infty}{0}$ & $\frac{m}{0}$ & $\overline{0}$ & $\underset{0}{\Delta}$ & స్ & ió. & $\frac{1}{0}$ & $\underset{\widetilde{\sigma}}{\tilde{0}}$ & $\stackrel{0}{0}$ & 웅 & ió. & $\frac{\infty}{0}$ & & \\
\hline & \multicolumn{2}{|c|}{ 迎 } & 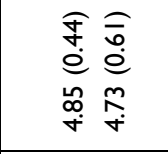 & 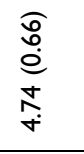 & 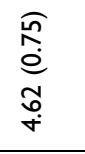 & $\begin{array}{l}\widehat{N} \\
\hat{c} \\
\infty \\
\stackrel{0}{+} \\
+\end{array}$ & $\begin{array}{l}\widehat{\hat{n}} \\
\stackrel{0}{0} \\
\stackrel{\infty}{+} \\
\dot{+}\end{array}$ & $\begin{array}{l}\widehat{D} \\
0 \\
0 \\
\infty \\
0 \\
\stackrel{+}{+}\end{array}$ & $\begin{array}{l}\widehat{\hat{T}} \\
\stackrel{0}{0} \\
\stackrel{\circ}{\circ} \\
\stackrel{+}{+}\end{array}$ & 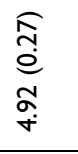 & $\begin{array}{l}\widehat{̃} \\
\stackrel{\text { }}{\infty} \\
\infty \\
\dot{+} \\
\end{array}$ & 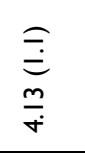 & $\begin{array}{l}\hat{n} \\
\hat{c} \\
\stackrel{0}{n} \\
\stackrel{+}{+}\end{array}$ & $\begin{array}{l}\hat{E} \\
\dot{e} \\
\dot{+} \\
\dot{+} \\
\end{array}$ & & 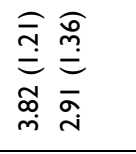 \\
\hline \multirow{3}{*}{ 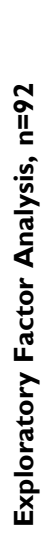 } & \multirow{2}{*}{ 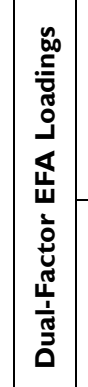 } & 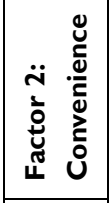 & $\frac{m}{0} \frac{n}{0}$ & สุ & $\frac{a}{0}$ & $\frac{1}{0}$ & $\frac{\pi}{0}$ & $\frac{\infty}{0}$ & ồ & $\frac{m}{0}$ & $\frac{0}{0}$ & $\frac{0}{0}$ & $\overline{\overline{0}}$ & $\frac{0}{0}$ & & $\begin{array}{l}\infty \\
0 \\
i\end{array}$ \\
\hline & & 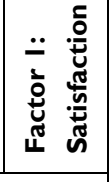 & స్. & 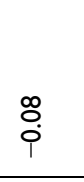 & 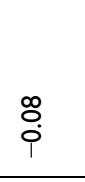 & o. & ర్ & O̊. & 훙 & 훙 & $\begin{array}{l}\text { Lo } \\
\text { i. }\end{array}$ & $\overline{0}$ & $\stackrel{8}{\circ}$ & $\stackrel{0}{\circ}$ & & $\underset{0}{\widetilde{0}} \overline{\overline{0}}$ \\
\hline & \multicolumn{2}{|c|}{ 造 氕 } & 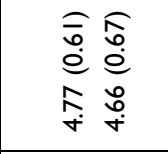 & 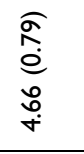 & $\begin{array}{l}\hat{n} \\
\hat{0} \\
o \\
\text { ô } \\
\dot{+}\end{array}$ & 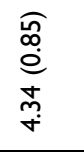 & 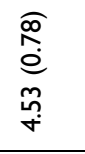 & $\begin{array}{l}\text { E్ } \\
0 \\
0 \\
0 \\
\stackrel{0}{+} \\
\end{array}$ & $\begin{array}{l}\widehat{\hat{N}} \\
\stackrel{\rho}{c} \\
\infty \\
\stackrel{+}{+} \\
\stackrel{+}{*}\end{array}$ & $\begin{array}{l}\frac{\mathfrak{q}}{b} \\
\stackrel{0}{0} \\
\stackrel{5}{+} \\
\dot{+}\end{array}$ & 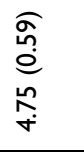 & $\begin{array}{l}\widehat{\sigma} \\
\stackrel{Ð}{\doteq} \\
o \\
o \\
\dot{+}\end{array}$ & $\begin{array}{l}\overparen{F} \\
\stackrel{\infty}{0} \\
\stackrel{0}{0} \\
\dot{+} \\
\dot{+}\end{array}$ & 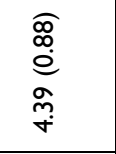 & & 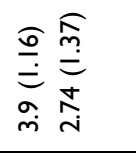 \\
\hline \multirow{3}{*}{\multicolumn{2}{|c|}{ 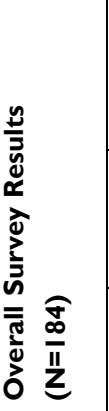 }} & z & 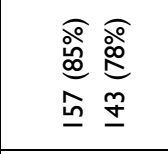 & $\begin{array}{l}\widehat{\curvearrowright} \\
\stackrel{5}{5} \\
\stackrel{0}{-}\end{array}$ & 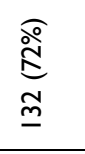 & $\begin{array}{l}\frac{\widehat{o}}{\underline{e}} \\
\frac{m}{=}\end{array}$ & 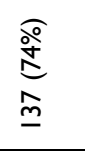 & 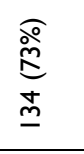 & 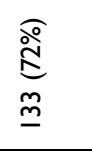 & 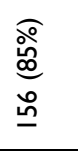 & 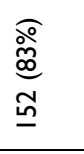 & 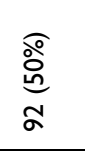 & 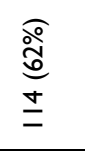 & 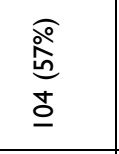 & & 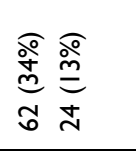 \\
\hline & & 㝴 & 00 & 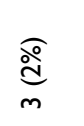 & 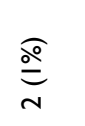 & $\stackrel{\circ}{\stackrel{\circ}{=}}$ & 0 & 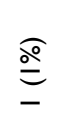 & 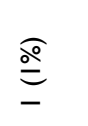 & 0 & 0 & 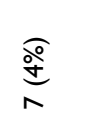 & 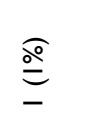 & $\stackrel{ð ゚}{\varrho}$ & & 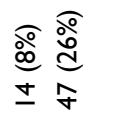 \\
\hline & & 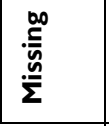 & No & N & r & N & r & $m$ & r & - & $n$ & $m$ & - & $\sim$ & & 00 \\
\hline & 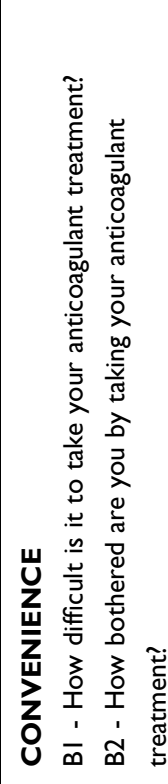 & 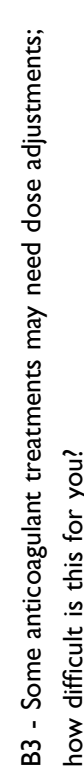 & 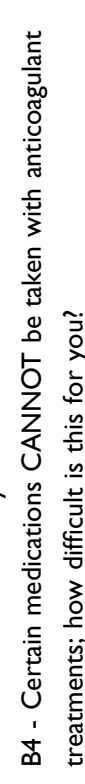 & 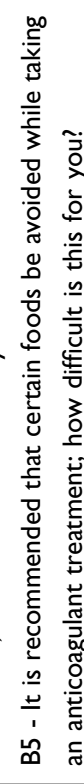 & 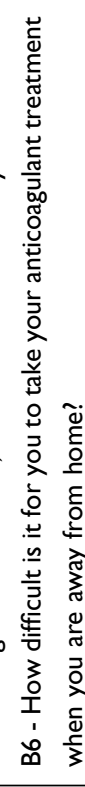 & 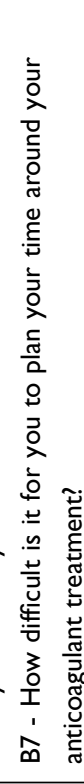 & 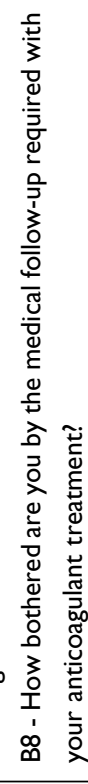 & 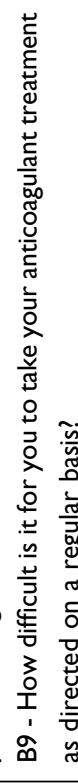 & 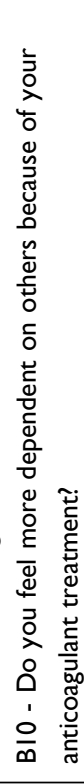 & 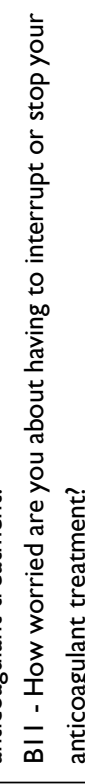 & 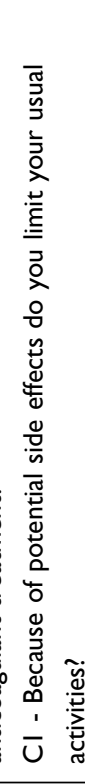 & 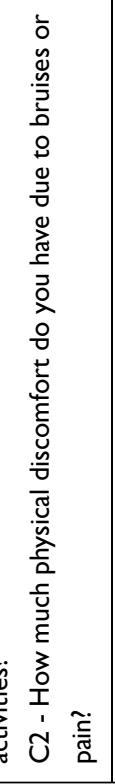 & 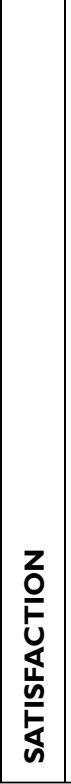 & 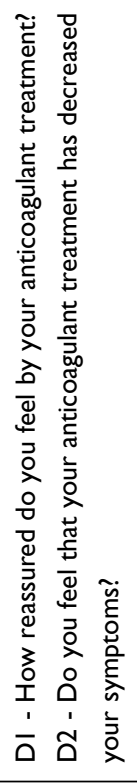 \\
\hline
\end{tabular}




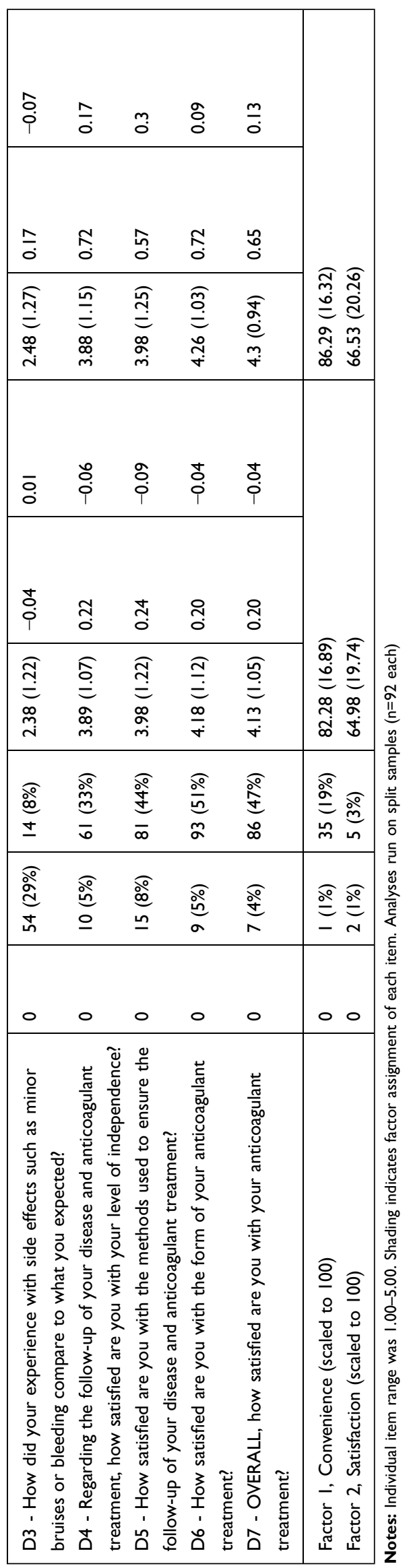

Table 3 Comparison of Convenience and Satisfaction by Drug Type $(n=184)$

\begin{tabular}{|l|l|l|}
\hline $\begin{array}{l}\text { PACT-Q2 } \\
\text { Results }\end{array}$ & $\begin{array}{l}\text { Convenience Mean } \\
\text { (SD) }\end{array}$ & $\begin{array}{l}\text { Satisfaction Mean } \\
\text { (SD) }\end{array}$ \\
\hline Overall mean & $87.88(16.69)$ & $67.86(19.96)$ \\
Apixaban & $86.08(15.58)$ & $69.16(18.16)$ \\
Dabigatran & $85.96(11.83)$ & $60.32(22.75)$ \\
Rivaroxaban & $92.47(7.43)^{*}$ & $68.96(18.69)$ \\
Warfarin & $81.09(18.8)^{*}$ & $64.24(20.49)$ \\
Combined & $87.62(13.10)^{\dagger}$ & $67.34(19.38)$ \\
DOACs & & \\
\hline
\end{tabular}

Notes: *Significant ANOVA result rivaroxaban vs warfarin, $p=0.022$. 'Significant $T$-test result between any DOAC vs warfarin, $\mathrm{p}=0.007$.

\section{Ability to Take Anticoagulant as Directed}

We found that most participants were able to take their anticoagulant (warfarin or a DOAC) as directed and did not find this to be challenging. For example, Veterans mentioned that they take more than one pill per day and thus, they can add the anticoagulant along with their other medications. As Veterans noted, taking their medications at a specific time, as well as understanding that taking multiple medications can have health benefits, can potentially help Veterans to take their medications as directed.

"[B]ased on age, I take more than one pill so I just add it to the rest of what I'm taking ... You know, dinner time comes you knock out a half a dozen pills." Veteran 1 taking warfarin

"I take about three other medications ... [Dabigatran] has become one of the [medicines] that I take and it's the right blend that's keeping me going." Veteran 12 taking a DOAC.

However, Veterans reported occasional challenges in taking their anticoagulant as directed. For example, although taking an anticoagulant was viewed to be relatively "straight forward," some Veterans needed to remember how many times to take the anticoagulant per day or remember what dose to take. In addition, there can be challenges with remembering to take the medication while on vacation or remembering information related to drug-drug interactions (eg, unable to take antiinflammatory drugs). Veterans noted what they have done to help them when they experience challenges, such as taking the medicine as soon as they remember and writing out a list of medications to take.

"I take it every night ... And if I forget to take it at night, I'll take it in the morning. You only take it once a day anyway." Veteran 3 taking warfarin 
"I keep a list and I write down morning and night what I take so I don't mess up." Veteran 6 taking warfarin

\section{Dietary Recommendation While Taking Anticoagulant} We also found that Veterans, particularly those taking warfarin, experienced challenges in following dietary recommendations while taking an anticoagulant. For example, one Veteran explained his initial worry when he started taking warfarin because he had to watch his vitamin $\mathrm{K}$ intake. In other cases, when laboratory monitoring (ie, International Normalized Ratio [INR]) revealed patients were out of therapeutic range due to variable consumption of vitamin K-rich foods (eg, broccoli) or alcohol, Veterans learned to adapt to recommended dietary guidance.

"[I] don't eat [my] broccoli so much. If I have broccoli and I love broccoli, then my [lab] levels would go down below 2. I mean below 2, just like 1.99. Or it might go up or down ... very little though, not to make me sick or anything. I won't eat broccoli and I love it." Veteran 5 taking warfarin

"If I'm scheduled to get an INR, I can kinda tell ahead of time that it's going to be off, because that was my own fault because I used to drink more than I should and my system sort of got used to drinking with [warfarin] ... So I just discontinued the alcohol, and everything came back into place." Veteran 17 taking warfarin

The two Veterans in our interview sample who had previously been taking warfarin and switched to a DOAC also confirmed similar challenges in following dietary recommendations when they had been prescribed warfarin. They found dietary compliance easier when taking a DOAC compared to warfarin because there were no dietary restrictions. One of the Veterans discussed his challenges in regulating his INR levels while on warfarin because he was drinking a beverage that had vitamin $\mathrm{K}$ in it. The other Veteran mentioned that his concerns about the dietary recommendations "went away" after switching to a DOAC.

"Yeah, the only thing when they first put me on [warfarin], for a while they had trouble regulating [INR levels] ... I worked outside and I drank a lot of [beverages with vitamin K]. And they never told me that vitamin $\mathrm{K}$ was a problem." Veteran 7 who switched from taking warfarin to a DOAC

"The concerns probably were more with warfarin in terms of the care you had to take with your diet. And all of a sudden, all of those concerns went away [after switching to a DOAC]." Veteran 12 who switched from taking warfarin to a DOAC

\section{Impact of Taking Anticoagulant on Daily Life}

Veterans also discussed how taking an anticoagulant may impact their daily life, particularly with warfarin and the need for regular INR testing. For example, one Veteran described how the impact on his life lessened when he retired. In contrast, another Veteran described that regular monitoring did not impact his schedule and that he adjusted to the travel, despite his home being farther away from the VA campus.

"Just the frequency of blood tests. But other than that, at this point, it's not as big an impact on my life as it was before. I'm now retired and so I can easily plan on a period of time when I can go into the VA. The VA campus is not that far from where I am. It's pretty convenient." Veteran 9 taking warfarin

"I really don't have a problem with [regular follow-up]. I mean it takes me almost an hour to go over to [the VA] to have the blood test but that's something that you just kinda get used to." Veteran 19 taking warfarin

Additionally, we found that Veterans on a DOAC expressed reduced impact on their life, given that there is no regularly required lab testing.

"Taking [dabigatran] is more simplistic and [I] wouldn't have to make those weekly, bi-weekly, monthly trips back to the VA." Veteran 12 who switched from taking warfarin to a DOAC

\section{Reaction to Laboratory Monitoring Required with Anticoagulant}

We found that participants felt positively about the regular laboratory monitoring required with warfarin. For example, a Veteran taking warfarin described that he was accustomed to getting blood tests and looked forward to the follow-up; to him, these visits were "like magic now." Another Veteran reported that it was a "pleasure" to go to the lab and get regular tests; knowing that his INR levels were in the correct range gave him a sense of achievement.

"I look forward to it because I know that if [the pharmacists] don't change anything, that it's all good. They tell me what my [INR] numbers have to be between 2-3 and it's a big success every time I go there it's what it's supposed to be." Veteran 4 taking warfarin 
On the other hand, despite the overall convenience of not needing as much monitoring on a DOAC compared to warfarin, a few Veterans on a DOAC desired more ongoing medical monitoring after the initial prescription than they were receiving. One participant who switched from warfarin to a DOAC summarized this reaction; while taking a DOAC was more convenient than warfarin, he felt that some additional monitoring may help if he had questions or concerns.

\begin{abstract}
"Well, warfarin was a real bother... I mean, going to the [warfarin] clinic ... You started out every week and once you started taking the drug and then if you were able to control your diet habits and your INR was good, then you went every two weeks and then out to a month. But the [dabigatran] I guess has worked so well that there just hasn't been the need or appeared to be a need to be checked. But on the other hand, it might be nice on an annual or semi-annual, or maybe every two years. Just something that's like, you know, the [dabigatran] is really working well, and there's no need for you to worry." Veteran 12 who switched from taking warfarin to a DOAC
\end{abstract}

\section{Satisfaction}

Overall, both groups of Veterans taking either warfarin or a DOAC reported their treatment to be satisfactory. Two main themes about satisfaction emerged from the data: 1) satisfaction with monitoring methods and 2) experience with side effects.

\section{Satisfaction with Monitoring Methods}

Overall, Veterans were satisfied with the monitoring methods used for anticoagulation management. Participants reported receiving their prescription via mail and had not experienced any challenges. Veterans described this method as "amazing" and "great" in which "the medicine always comes on time so I don't have to miss it." In addition, those taking warfarin reported that regular monitoring of INR levels alleviated their concerns about the anticoagulation treatment (eg, not knowing if INR levels are in therapeutic range or potential risk of adverse drug events). We found that this was one of the main reasons why some Veterans continued to take warfarin as their anticoagulant instead of switching to a DOAC.

\footnotetext{
"Again I have no symptoms. With the other medications there is no testing so how would you know if something's wrong ... [I]t takes you ten minutes and you're done. That way somebody is looking at it and if there is a problem, they will let me know ... I'm satisfied with what I'm doing that somebody else is monitoring me." Veteran 1 taking warfarin
}

In contrast, participants taking a DOAC reported satisfaction in monitoring methods because they did not have to get regular INR testing. However, those Veterans who had switched from warfarin and were now taking a DOAC expressed uncertainties with not knowing about how their treatment was going without ongoing monitoring.

"I didn't have to go for a blood test for like six months. You know, if having [INR levels within range was] gonna be easier or not easier, I wouldn't know for six months." Veteran 7 who switched from taking warfarin to a DOAC

"Another aspect about being on this drug is and doing it the way I have now is there [is] no [specific] feedback." Veteran 12 who switched from taking warfarin to a DOAC

\section{Experience with Side Effects}

For most participants, Veterans' experiences with side effects, such as bleeding and bruising, did not affect their satisfaction. Veterans perceived that the benefits of taking the anticoagulant outweighed the side effects. Some participants taking warfarin discussed how they were initially concerned about the side effects; however, they became more aware of what they "should or should not be doing" as they continued to take the anticoagulant.

"I guess the only thing was I really didn't understand the significance of running into something ... I was running to the car and didn't see a chain going across this driveway. And so I ran into the chain and the next morning I was probably black and blue from my knees all the way up to my stomach. Yeah, so you immediately learn what you should or should not be doing. Not because you're told but because of an accident like I had. I knew something was gonna happen, I just didn't know it was gonna be that extensive." Veteran 9 taking a warfarin

In contrast, one Veteran expressed dissatisfaction in taking a DOAC because of his experiences with severe bleeding and wanted to be taking a different anticoagulant. This participant reported challenges in managing the bleeding. Although he had discussed possible changes to his medication and dose with his clinician, he decided to continue to take a DOAC because he could still experience side effects, such as bleeding, with other anticoagulants; he felt that there were no other treatment options.

"I want to prevent a stroke and at the same time that means I have to put up with possibility of bleeding. Like I said, I keep repeating [to clinician] if [another anticoagulant] finally comes up that is something brand new that does the same job, without the side liability story [risk 
of bleeding], I would be interested." Veteran 14 taking a DOAC

\section{Discussion}

In our exploratory analysis of patient perceptions of convenience and satisfaction with anticoagulant medication for AFib, we found that Veterans over age 65 years and dually enrolled in VA and Medicare were most commonly prescribed DOACs as initial treatment or had been switched to DOACs from warfarin in 2018. Respondents to the PACT-Q2 survey rated convenience significantly higher for DOACs than warfarin and we observed no significant difference in satisfaction ratings between the anticoagulation drug types. Overall, average satisfaction ratings for all anticoagulants were lower than average convenience ratings ( $88 \%$ versus $68 \%$ ). Interview results further confirmed that patients were mostly satisfied with whichever drug they were taking, although differences in the experience of side effects and the perceived benefit of the medication influenced convenience ratings.

Our findings differed somewhat from other studies of AFib patients taking anticoagulants. Earlier studies with the PACT-Q2 found that patients rated convenience higher than satisfaction across all anticoagulants, as we did; ${ }^{21}$ however, we only found significantly higher convenience scores, not satisfaction scores, for DOACs compared to warfarin. This inconsistency is potentially due to differences in patient populations. For instance, studies in Asia and Europe found significantly higher satisfaction scores for DOACs according to PACT-Q2 than for warfarin. $^{14,23,24,29}$ These studies included patients aged 18 and older, and with fewer comorbidities, particularly mental health concerns, than patients treated in the VA. ${ }^{30}$ By assessing the perspectives of VA patients with dementia or serious mental illness residing in non-institutional settings, we made a meaningful contribution to the literature as these vulnerable patients are often overlooked in research. Variation in results from our study population and prior work highlights the need to assess perspectives in diverse groups of patient with AFib to accurately inform shared decision-making. ${ }^{17}$

Prior qualitative work showed patients typically preferred the anticoagulant they were using. ${ }^{1,15}$ Our interview results also found that patients taking warfarin or DOACs preferred the drug they were using and did not find issues with convenience or satisfaction significant enough to want a different medication. In the few interview respondents who had been switched from warfarin to DOACs, the change in treatment may have had clinical advantages, but some patients were willing to forego convenience (due to need for monitoring) in exchange for the increased satisfaction provided by laboratory feedback. While there are medical conditions that make warfarin the first choice in treatment, ${ }^{18,19}$ for many AFib patients, clinicians are likely to prescribe DOACs. ${ }^{6}$ In a study of Veterans newly diagnosed with AFib, patients wanted to be part of the decision-making process with respect to which anticoagulant they would use and that their preferences were based on their values. ${ }^{13}$ Clinicians should consider patient preferences before switching medications, as something perceived to be a burden by the clinician may be associated with patient satisfaction. ${ }^{15,18}$ Newer tools to facilitate shared decisionmaking around AF treatment may also help clinicians and patients arrive at the optimal treatment plan. ${ }^{31}$ Ensuring that Veterans switching from warfarin to a DOAC still have interval follow-up with a clinician may help mitigate Veterans' concerns while maintaining satisfaction with treatment.

Our study has several strengths and limitations. We add to other studies providing evidence that the PACT-Q2 reliably measures patient's perceptions of satisfaction and convenience with respect to their anticoagulation use. ${ }^{14,23-25,29}$ As more evidence develops regarding the value of various novel anticoagulant medications, the PACT-Q2 may continue to provide utility in assessing patient perceptions. Our study also has the advantage of including qualitative interviews to further understand the factors underlying convenience and satisfaction ratings in the survey. While the study was limited to a small geographic area in the US, we explored patient perceptions in an understudied subpopulation: Veterans with AFib. Further qualitative research with a larger Veteran sample size that includes factors related to preferences, including cost and harms, may provide additional useful information for clinical care.

The survey and qualitative interview results of this study confirm that patient perceptions of satisfaction and convenience with DOACs and warfarin vary. Higher convenience scores and no difference in satisfaction ratings suggest that DOACs are an appropriate alternative to warfarin when clinically indicated for this subpopulation of aged 65 and older Veterans with AFib; however, patient perceptions were based on a variety of factors and some patients clearly preferred warfarin. Veteran's perceptions of convenience and satisfaction differ from published ratings in other patient populations, and underlying factors 
elicited through interviews further reinforce the importance of shared decision-making for anticoagulation treatment in the absence of consensus recommendations.

\section{Disclosure}

The authors report no conflicts of interest in this work.

\section{References}

1. Danelich IM, Reed BN, Hollis IB, Cook AM, Rodgers JE. Clinical update on the management of atrial fibrillation. Pharmacotherapy. 2013;33(4):422-446. doi:10.1002/phar.1217

2. Quinn GR, Fang MC. Atrial fibrillation: stroke prevention in older adults. Clinics in Geriatric Medicine. 2012;28(4):617-634.

3. Lu Y, Branstad R, Karim RM, Asinger RW. Consideration of clinical variables for choosing new anticoagulant alternatives to warfarin for the management of non-valvular atrial fibrillation. Journal of Clinical Pharmacy and Therapeutics. 2014;39(6):628-636. doi:10.1111/ jcpt. 12207

4. Proietti M, Lane DA, Boriani G, Lip GYH. Stroke Prevention, Evaluation of Bleeding Risk, and Anticoagulant Treatment Management in Atrial Fibrillation Contemporary International Guidelines. Can J Cardiol. 2019;35(5):619-633. doi:10.1016/j.cjca.2019.02.009

5. Ruff CT, Giugliano RP, Braunwald E, et al. Comparison of the efficacy and safety of new oral anticoagulants with warfarin in patients with atrial fibrillation: a meta-analysis of randomised trials. Lancet. 2014;383(9921):955-962. doi:10.1016/S0140-6736(13)62343-0

6. Munn D, Abdul-Rahim AH, Fischer U, Werring DJ, Robinson TG, Dawson J. A survey of opinion: when to start oral anticoagulants in patients with acute ischaemic stroke and atrial fibrillation? Eur Stroke J. 2018;3(4):355-360. doi:10.1177/2396987318787124

7. Devereaux PJ, Anderson DR, Gardner MJ, et al. Differences between perspectives of physicians and patients on anticoagulation in patients with atrial fibrillation: observational study Commentary: varied preferences reflect the reality of clinical practice. BMJ (Clinical Research Ed. 2001;323(7323):1218-1222. doi:10.1136/bmj.323.7323.1218

8. Borg Xuereb C, Shaw RL, Lane DA. Patients' and health professionals' views and experiences of atrial fibrillation and oralanticoagulant therapy: a qualitative meta-synthesis. Patient Educ Couns. 2012;88(2):330-337. doi:10.1016/j.pec.2012.05.011

9. Larochelle J, Brais C, Blais L, et al. Patients' Perception of Newly Initiated Oral Anticoagulant Treatment for Atrial Fibrillation: an Observational Study. J Gen Intern Med. 2018;33(8):1239-1241. doi:10.1007/s11606-018-4457-z

10. Mas Dalmau G, Sant Arderiu E, Enfedaque Montes MB, Sola I, Pequeno Saco S, Alonso Coello P. Patients' and physicians' perceptions and attitudes about oral anticoagulation and atrial fibrillation: a qualitative systematic review. BMC Family Practice. 2017;18(1):3. doi:10.1186/s12875-016-0574-0

11. Bajorek B, Saxton B, Anderson E, Chow CK. Patients' preferences for new versus old anticoagulants: a mixed-method vignette-based study. Eur J Cardiovasc Nurs. 2018;17(5):429-438. doi:10.1177/ 1474515117739618

12. Boom MS, Berghuis EM, Nieuwkerk PT, Pinedo S, Buller HR. When do patients prefer a direct oral anticoagulant over a vitamin $\mathrm{K}$ antagonist? Neth J Med. 2015;73(8):368-372.

13. Palacio AM, Kirolos I, Tamariz L. Patient values and preferences when choosing anticoagulants. Patient Prefer Adherence. 2015;9:133-138.

14. Ng DL-C, Gan -G-G, Chai C-S, et al. $<$ p $>$ Comparing quality of life and treatment satisfaction between patients on warfarin and direct oral anticoagulants: a cross-sectional study. Patient Prefer Adherence. 2019;13:1363-1373. doi:10.2147/PPA.S204246
15. Wright JN, Vazquez SR, Kim K, Jones AE, Witt DM. Assessing patient preferences for switching from warfarin to direct oral anticoagulants. Journal of Thrombosis and Thrombolysis. 2019;48 (4):596-602. doi:10.1007/s11239-019-01915-9

16. MacLean S, Mulla S, Akl EA, et al. Patient values and preferences in decision making for antithrombotic therapy: a systematic review: antithrombotic Therapy and Prevention of Thrombosis, 9th ed: american College of Chest Physicians Evidence-Based Clinical Practice Guidelines. Chest. 2012;141(2):e1S-e23S. doi:10.1378/chest.11-2290

17. Seaburg L, Hess EP, Coylewright M, Ting HH, McLeod CJ, Montori VM. Shared decision making in atrial fibrillation: where we are and where we should be going. Circulation. 2014;129 (6):704-710. doi:10.1161/CIRCULATIONAHA.113.004498

18. Prisco D, Cenci C, Silvestri E, Ciucciarelli L, Di Minno G. Novel oral anticoagulants in atrial fibrillation: which novel oral anticoagulant for which patient? J Cardiovasc Med (Hagerstown). 2015;16 (7):512-519. doi:10.2459/JCM.0000000000000262

19. Turagam MK, Velagapudi P, Flaker GC. Stroke prevention in the elderly atrial fibrillation patient with comorbid conditions: focus on non-vitamin $\mathrm{K}$ antagonist oral anticoagulants. Clin Interv Aging. 2015;10:1431-1444.

20. Olenick M, Flowers M, Diaz VJ. US veterans and their unique issues: enhancing health care professional awareness. Adv Med Educ Pract. 2015;6:635-639. doi:10.2147/AMEP.S89479

21. Prins MH, Guillemin I, Gilet H, et al. Scoring and psychometric validation of the Perception of Anticoagulant Treatment Questionnaire (PACT-QC). Health Qual Life Outcomes. 2009;7 (1):30. doi:10.1186/1477-7525-7-30

22. Prins $\mathrm{MH}$, Marrel A, Carita $\mathrm{P}$, et al. Multinational development of a questionnaire assessing patient satisfaction with anticoagulant treatment: the 'Perception of Anticoagulant Treatment Questionnaire' (PACT-QC). Health Qual Life Outcomes. 2009;7(1):9. doi:10.1186/1477-7525-7-9

23. Benzimra M, Bonnamour B, Duracinsky M, et al. Real-life experience of quality of life, treatment satisfaction, and adherence in patients receiving oral anticoagulants for atrial fibrillation. Patient Prefer Adherence. 2018;12:79-87. doi:10.2147/PPA.S131158

24. Goette A, Kwong WJ, Ezekowitz MD, et al. Edoxaban therapy increases treatment satisfaction and reduces utilization of healthcare resources: an analysis from the EdoxabaN vs. warfarin in subjectS UndeRgoing cardiovErsion of atrial fibrillation (ENSURE-AF) study. Europace. 2018;20(12):1936-1943. doi:10.1093/europace/euy141

25. Riva N, Borg Xuereb C, Makris M, Ageno W, Gatt A. $<$ p $>$ Reliability and validity of the Maltese version of the Perception of Anticoagulant Treatment Questionnaire (PACT-Q). Patient Prefer Adherence. 2019;13:969-979. doi:10.2147/PPA.S207498

26. Healthcare Cost and Utilization Project (HCUP). AHRQ Comorbidity Software, Version 3.7. http://www.hcup-us.ahrq.gov/toolssoftware/ comorbidity/comorbidity.jsp.2017. Accessed May 13, 2013.

27. Dillman D. Mail and Internet Surveys: The Tailored Design Method. 2nd ed. New York: John Wiley \& Sons, Inc; 2000.

28. Holder KA. United States Census Bureau, Social, Economic and Housing Statistics Division: Who Are Veterans? 2016. Available from https://www.census.gov/newsroom/blogs/random-samplings/ 2016/11/who are veterans.html. Accessed October 09, 2020.

29. Chen J, Zhuang X, Long M, Su C, Wang WL. Efficacy and Safety of Edoxaban in Nonvalvular Atrial Fibrillation: A Meta-analysis of Randomized Controlled Trials. J Stroke Cerebrovasc Dis. 2015;24 (12):2710-2719. doi:10.1016/j.jstrokecerebrovasdis.2015.07.026

30. Petersen H, Mental Health VA Featured Article: late Life Depression. https://www.mentalhealth.va.gov/featureArticle_Mar11LateLife.asp. 2011. Accessed Oct 21, 2019..

31. Noseworthy PA, Brito JP, Kunneman M, et al. Shared decision-making in atrial fibrillation: navigating complex issues in partnership with the patient. $J$ Int Cardiac Electrophysiol. 2019;56 (2):159-163. doi:10.1007/s10840-018-0465-5 


\section{Publish your work in this journal}

Patient Preference and Adherence is an international, peer-reviewed, open access journal that focusing on the growing importance of patient preference and adherence throughout the therapeutic continuum. Patient satisfaction, acceptability, quality of life, compliance, persistence and their role in developing new therapeutic modalities and compounds to optimize clinical outcomes for existing disease

states are major areas of interest for the journal. This journal has been accepted for indexing on PubMed Central. The manuscript management system is completely online and includes a very quick and fair peer-review system, which is all easy to use. Visit http:// www.dovepress.com/testimonials.php to read real quotes from published authors. 